\title{
Kinetic Release Studies of Antibiotic Patches for Local Transdermal Delivery
}

\author{
Esra Altun ${ }^{1}$, Esra Yuca ${ }^{2}$, Nazmi Ekren ${ }^{3}$, Deepak M. Kalaskar ${ }^{4, *}{ }^{\circledR}$, Denisa Ficai ${ }^{5,6} \oplus$, Georgiana Dolete ${ }^{6,7}$, \\ Anton Ficai ${ }^{6,7,8, *(\mathbb{D})}$ and Oguzhan Gunduz $1, *$ (1)
}

1 Centre for Nanotechnology \& Biomaterials Research, Department of Metallurgical and Materials Engineering, Faculty of Technology, Goztepe Campus, Marmara University, Istanbul 34722, Turkey; esra.altun@ymail.com

2 Department of Molecular Biology and Genetics, Faculty of Arts and Sciences, Davutpasa Campus, Yildiz Technical University, Istanbul 34220, Turkey; eyuca@yildiz.edu.tr

3 Centre for Nanotechnology \& Biomaterials Research, Department of Electrical-Electronics Engineering, Faculty of Technology, Goztepe Campus, Marmara University, Istanbul 34722, Turkey; nazmiekren@marmara.edu.tr

4 UCL Division of Surgery and Interventional Science, Royal Free Hospital Campus, University College London, Rowland Hill Street, London NW3 2PF, UK

5 Department of Inorganic Chemistry, Physical Chemistry and Electrochemistry, Faculty of Applied Chemistry and Materials Science, University POLITEHNICA of Bucharest, 060042 Bucharest, Romania; denisaficai@yahoo.ro

6 National Centre for Micro- and Nanomaterials, University POLITEHNICA of Bucharest, 060042 Bucharest, Romania; dolete.georgiana@gmail.com

7 Department of Science and Engineering of Oxide Materials and Nanomaterials, Faculty of Applied Chemistry and Materials Science, University POLITEHNICA of Bucharest, 060042 Bucharest, Romania

check for updates

Citation: Altun, E.; Yuca, E.; Ekren, N.; Kalaskar, D.M.; Ficai, D.; Dolete, G.; Ficai, A.; Gunduz, O. Kinetic Release Studies of Antibiotic Patches for Loca Transdermal Delivery. Pharmaceutics 2021, 13, 613. https://doi.org/ $10.3390 /$ pharmaceutics 13050613

Academic Editors: Marcel Popa and Anca Niculina Cadinoiu

Received: 15 March 2021

Accepted: 19 April 2021

Published: 23 April 2021

Publisher's Note: MDPI stays neutral with regard to jurisdictional claims in published maps and institutional affiliations.

Copyright: (C) 2021 by the authors Licensee MDPI, Basel, Switzerland. This article is an open access article distributed under the terms and conditions of the Creative Commons Attribution (CC BY) license (https:// creativecommons.org/licenses/by/ $4.0 /)$.
8 Academy of Romanian Scientists, 060042 Bucharest, Romania

* Correspondence: d.kalaskar@ucl.ac.uk (D.M.K.); anton.ficai@upb.ro (A.F.); ucemogu@ucl.ac.uk (O.G.)

\begin{abstract}
This study investigates the usage of electrohydrodynamic (EHD)-3D printing for the fabrication of bacterial cellulose (BC)/polycaprolactone (PCL) patches loaded with different antibiotics (amoxicillin (AMX), ampicillin (AMP), and kanamycin (KAN)) for transdermal delivery. The composite patches demonstrated facilitated drug loading and encapsulation efficiency of drugs along with extended drug release profiles. Release curves were also subjected to model fitting, and it was found that drug release was optimally adapted to the Higuchi square root model for each drug. They performed a time-dependent and diffusion-controlled release from the patches and followed Fick's diffusion law by the Korsmeyer-Peppas energy law equation. Moreover, produced patches demonstrated excellent antimicrobial activity against Gram-positive (Staphylococcus aureus) and Gram-negative (Escherichia coli) strains, so they could be helpful in the treatment of chronic infectious lesions during wound closures. As different tests have confirmed, various types of antibiotics could be loaded and successfully released regardless of their types from produced BC/PCL patches. This study could breathe life into the production of antibiotic patches for local transdermal applications in wound dressing studies and improve the quality of life of patients.
\end{abstract}

Keywords: electrohydrodynamic printing; antibiotic patches; drug release; polymer; bacterial cellulose

\section{Introduction}

Proper wound management is essential to guard wounded areas from pathogens responsible for secondary infections. For example, if germs rapidly multiply in a wound, and the infection spreads, it could cause a serious internal infection [1]. Moreover, an internal infection can delay wound healing by extending the inflammatory stage while the immune system responds and clears the infection [2]. In this respect, antibiotic patches are an innovative approach, i.e., to deliver improved healthcare, reduce overall healthcare costs, increase drug effectiveness, and balance the toxicity of drugs involved in local wound 
management [3]. They are essential in managing local infections where high concentrations of antibiotics are required locally [4]. On the other hand, their concentrations in the patches should be kept under control as high amounts of antibiotics can lead to systemic toxicity [5]. Beta-lactam antibiotics (amoxicillin, ampicillin) and aminoglycosides (kanamycin) are well-known drugs applied to inhibit bacterial spread in wound dressing applications [6]. Their loadings into transdermal patches for local wound dressing applications can provide beneficial antibacterial activity while being absorbed into the body. Furthermore, local administration can limit the potential for systemic absorption of antibiotics, diminishing antibiotic resistance [6].

Drug delivery systems have been extensively explored in recent decades to provide more effective and side effect-free treatments for patients suffering from diseases. The most common forms of drug delivery systems include oral tablets, liquid injections, microspheres, hydrogels, liposomes, micelles, and nanoparticles [7]. However, such delivery systems have challenges in maintaining precise control of the rate and duration of drug release, require repeated administration, and have long-term release problems [8-13]. To overcome these difficulties, drug embedded thin polymer patches have been proposed as a versatile approach to prolong drug release, and they are currently being widely used [14]. Thin polymer patches are flexible and can be produced in various shapes and sizes [15]. Three-dimensional (3D) printers, such as inkjet printers and thermal inject printers, can create small-sized patches (with high placement accuracy) using thermal or mechanical actuating mechanisms [16]. However, inkjet printing is limited in writing operations that involve small micrometers, and cannot be utilized for drug reservoirs requiring several micrometers [17]. The electrohydrodynamic (EHD)-3-dimensional (3D) printing method is capable of achieving micrometer-scale, complex, high-resolution 3D structures, in ambient temperature operations, with single-step productions [18]. The EHD uses an electric field on the polymer solution using micro/nano-scaled nozzle tips [19]. The EHD-3D printing process is the same as the conventional EHD process, yet the sample is collected close to the needle, which is quite small in diameter. Therefore, it is possible to achieve higher print resolution without replacing the nozzle tip with a smaller diameter nozzle, using highly viscous colloidal solutions, or viscous polymeric fluids [20]. Moreover, the EHD-3D printing method can provide essential leads for cell alignment and cell contact guidance, for better cell proliferation and tissue formation, with optimal porosity, inter-fibrous pore size, and pore distribution [21-23]. The dosage of the antibiotics can be adjusted according to the patient's individual needs by altering the size of the EHD-3D printed scaffolds and the content of the solid materials. In addition, through EHD-3D printing, the formulation can be achieved during the production and purification of the drugs, improving efficiency, and decreasing the costs for pharmaceuticals industries.

Polymeric biomaterials and composites are widely used in the EHD-3D printing method due to their polymerizing capabilities, by various methods, to make them "3D printable". They provide physical support for cell attachment, but they also offer transport of therapeutic agents, such as drugs, proteins, growth factors, and chemical agents [24]. PCL is one of the biomaterials that has semi-crystalline, biocompatible, and biodegradable features, with ideal mechanical properties and biological performance [25]. The usage of PCL in drug dosage forms is quite common due to its ability to be easily absorbed into the porous structure of the drug active substance, its capability of returning the active substance to the body at high rates, its complete resorption from the body, and its extended bioavailability on the tissue [26]. The high biocompatibility and slow(er) biodegradation rate, as well as the required flexibility of PCL, make it applicable for use in local transdermal applications. Furthermore, PCL patches show great potential for the delivery of therapeutics, and they can be combined with other biomaterials, such as bacterial cellulose (BC). BC is a biomaterial that shares common features with extracellular matrix (ECM) components [27]. Its porosity can provide the release of antimicrobial agents, drugs, and other bio-functional materials to the targeted tissue in a controlled manner $[28,29]$. Blending this remarkable polymer with PCL can offer improved cell 
viability rates while an antibiotic patch releases its therapeutic agent [30]. Moreover, thanks to the hydrophilic nature of BC, moisture can be maintained, and dehydration of the wound and crust formation can be prevented.

This research aims to produce layer-on-layer stacked antibiotic patches from BC/PCL blend polymers carrying various broad-spectrum antibiotics using the EHD-3D printing method, and compare their releasing properties with drug release studies and drug release kinetic models for local transdermal applications in wound dressing applications. The use of these antibiotics will exhibit the versatility of the antibiotic patches in terms of different antibiotic loadability.

\section{Materials and Methods}

\subsection{Materials}

Polycaprolactone (PCL, Mw 80,000 g/mol), dimethylformamide (DMF), and dichloromethane (DCM) were purchased from Sigma-Aldrich (St. Louis, MO, USA). Bacterial cellulose (BC) pellicle was provided by the Department of Medical Microbiology, Medipol University (Istanbul, Turkey). Amoxicillin (AMX, Mw 365.4 g/mol), ampicillin (AMP, Mw $349.4 \mathrm{~g} / \mathrm{mol}$ ), kanamycin (KAN, Mw $600.6 \mathrm{~g} / \mathrm{mol}$ ), and phosphate buffered saline (PBS, pH 7.4) were also obtained from Sigma-Aldrich (Steinheim, Germany).

\subsection{Preparation of Solutions}

BC pellicle was sonicated in DMF for $1 \mathrm{~h}$ using a sonicator (Branson Sonifier 250, BRANSON, Danbury, CT, USA) at a power output of $100 \%$ and then was centrifuged at $6000 \mathrm{rpm}$ for $600 \mathrm{~s}$. After each centrifugation step, the supernatant was removed and, finally, fragmented BC was obtained with almost no DMF residue. After that, $10 \mathrm{wt} \%$ PCL solution was prepared in DCM with continuous magnetic stirring (WiseStir ${ }^{\circledR}, \mathrm{MSH}-20 \mathrm{~A}$, Germany) for $24 \mathrm{~h}$ at $23^{\circ} \mathrm{C}$. As the last step, fragmented BC was blended with $10 \mathrm{wt} \% \mathrm{PCL}$ solution (5:95 wt. ratio), and the final blend was magnetically stirred for $1 \mathrm{~h}$ at an ambient temperature $\left(23^{\circ} \mathrm{C}\right)$.

The direct blending of the drug with a polymeric solution is the simplest method for fabricating drug-containing patches through the processing of a polymeric [31]. Therefore, three different types of antibiotics (AMX, AMP, and KAN) were individually blended with $\mathrm{BC} / \mathrm{PCL}$ solution under constant stirring at an ambient temperature $\left(23^{\circ} \mathrm{C}\right)$ for $12 \mathrm{~h}$ prior to EHD-3D printing. The initial loading of each drug was $50 \mathrm{mg} / \mathrm{mL}$. After blending, final solutions were stirred at an ambient temperature $\left(23^{\circ} \mathrm{C}\right)$ for another $12 \mathrm{~h}$ before EHD-3D printing. Prepared solutions were measured for their viscosity, density, electric conductivity, and surface tension using a Brookfield DV-E programmable viscometer, a standard density bottle (5 mL), a KRÜSS K100SF tensiometer, and a WTW Cond-3110-SET1 conductivity meter, respectively. The measurements were carried out in triplicate at the ambient temperature of $23{ }^{\circ} \mathrm{C}$ and relative humidity of $50 \pm 3 \%$.

\subsection{EHD-3D Printing}

The EHD-3D printing was accomplished by using an altered lab system, which consisted of an $\mathrm{X}-\mathrm{Y}$ stage motion control head, a glass substrate holder, a nozzle holder with Z-axis control, a high voltage power supply (output DC voltage from 0 to $40 \mathrm{kV}$ ), and a solution feeding system (Figure 1). The solution feeding system consisted of a programmable syringe pump (NE-1000, New Era Pump System Inc., Farmingdale, NY, USA) and a stainless steel nozzle (with $21 \mathrm{G}$ orifice). The syringe was filled with a prepared solution, which gave a constant solution source through the EHD-3D printing process. 


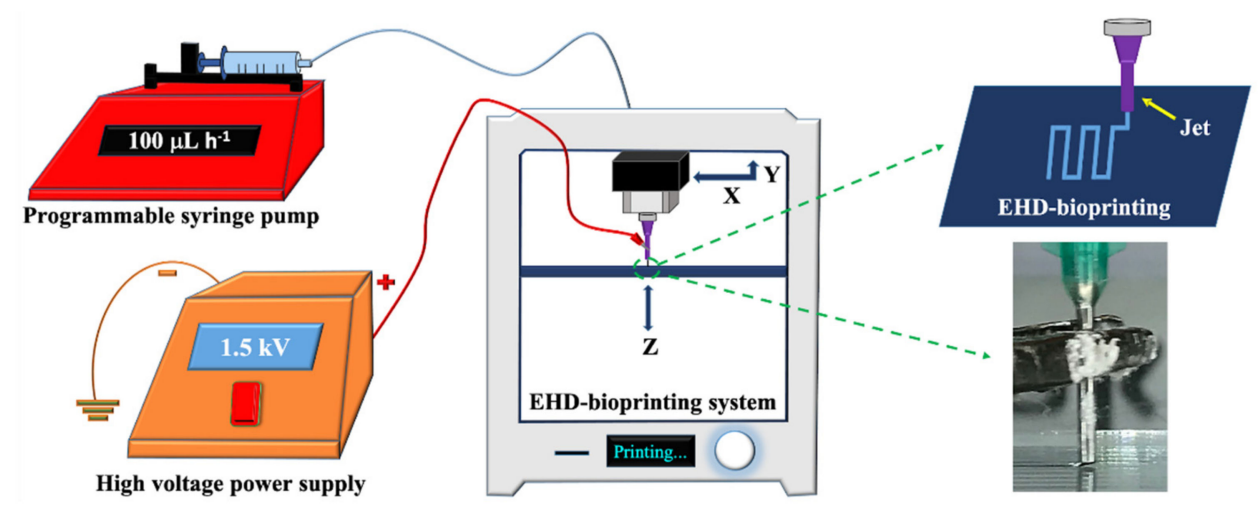

Figure 1. Experimental EHD-3D printing setup with a closer view of the EHD-3D patterning.

For EHD-3D printing, SolidWorks software was used to design the square patches as $10 \times 10 \mathrm{~mm}^{2}$, and layers were piled in $5 \mathrm{~min}$ with a $90^{\circ}$ angle as pre-designed. The distance between the nozzle and substrate was stabilized to $1 \mathrm{~mm}$ for experimental setup after the preliminary investigations [23,30]. According to the study, as mentioned earlier, the flow rate was optimized for reproducible and uniform fiber formation to $100 \mathrm{mLh}^{-1}$ for all samples. EHD-3D printed microfibers were deposited using $1.5 \mathrm{kV}$ and stacked with $0^{\circ} / 90^{\circ}$ angles as two layers. Upon completing the EHD-3D printing process, drug patches were removed from the substrate. The vacuum oven was used to evaporate residue solvents that may have remained in the samples before characterization tests. Finally, yield percentages of samples were calculated using Equation (1) and all calculations were repeated three times:

Yield $\%=100 \times($ weight of collected product $/$ weight of solid materials applied $)$

\subsection{Characterization of Drug Patches}

Morphological characterization of the neat and the drug-containing patches was investigated by a ZEISS MA/EVO10 scanning electron microscope (SEM). Samples were placed on microscopic glass slides and mounted on a specimen stub with double-sided carbon tape. Then, they were sputter-coated with Au for $60 \mathrm{~s}$ using a Quorum SC7620 Mini Sputter Coater before SEM imaging. After SEM imaging at an acceleration voltage of $10 \mathrm{kV}$, diameters of the individual fibers, inter-fibrous pore sizes, and porous sizes and porosity on the fibers within the EHD-3D printed patches were measured using ImageJ.

A JASCO FT/IR-4000 Fourier transform infrared spectrometer (FTIR) was used to investigate the chemical characterization of the EHD-3D printed patches. Each FTIR spectra was taken at $4 \mathrm{~cm}^{-1}$ resolution over the range of $4000-400 \mathrm{~cm}^{-1}$.

Uniaxial tensile tests were performed using an INSTRON 4411 tensile device (Instron, Norwood, MA, USA) with a $50 \mathrm{~N}$ load cell under a crosshead speed of $5 \mathrm{~mm} / \mathrm{min}$ at the ambient temperature $\left(23^{\circ} \mathrm{C}\right)$. All patches were subjected to tensile testing. Each measurement was taken in triplicate, and the ultimate tensile strength and Young's modulus values were calculated from the stress-strain curves of the tested samples.

The swelling characteristics of the EHD-3D printed patches were measured according to Equation (2) after the samples were submerged in PBS at $37^{\circ} \mathrm{C}$ for $24 \mathrm{~h}$ :

$$
\text { Degree of swelling }(\%)=100 \times(\mathrm{M}-\mathrm{Md}) / \mathrm{Md}
$$

where $\mathrm{M}$ is the weight of each sample after submersion in the PBS solution for $24 \mathrm{~h}$ and $\mathrm{Md}$ is the weight of the sample after submersion in the buffer solution for $24 \mathrm{~h}$ in its dry state.

Prior to AMX, AMP, and KAN drug loading (DL) and encapsulation efficiency (EE) studies, all drug-containing patches were utterly dissolved in DCM. Thereafter, AMX, AMP, and KAN concentrations in DCM were determined using UV Spectrophotometer (UV1280, 
Shimadzu, Kyoto, Japan) at 229, 230 and $207 \mathrm{~nm}$. The DL and EE percentages of AMX, AMP, and KAN in patches were calculated using Equations (3) and (4) [31]:

$$
\begin{aligned}
\mathrm{DL}(\%) & =100 \times(\text { Weight of antibiotic entrapped in the sample/weight of the patch }) \\
& \mathrm{EE}(\%)=100 \times(\text { Determined drug content/theoretical drug content })
\end{aligned}
$$

\subsection{Drug Release Studies}

The in vitro release kinetics of antibiotics from EHD-3D printed patches in PBS medium were determined using a UV Spectroscopy by recording the wavelengths at 229, 230 and $207 \mathrm{~nm}$ for AMX, AMP, and KAN, respectively. A linear calibration curve was established based on standard solutions with concentrations ranging from 5-200 $\mu \mathrm{g} / \mathrm{mL}$. The amount of the drug present in a patch was calculated from the obtained calibration curve for each drug. All drug-release experiments were carried out using the total immersion method with a known quantity of sample immersed in a sealed vial bottle containing $20 \mathrm{~mL}$ of PBS and incubated in a shaker at a constant incubation temperature $37^{\circ} \mathrm{C}$. At designated time intervals ranging between 0 and 14 days $(336 \mathrm{~h})$, a $1 \mathrm{~mL}$ release medium was taken out and replenished with an equal volume of fresh PBS. Supernatants were filtered using $0.45 \mu \mathrm{m}$ Millipore. The amount of the drugs in the withdrawn release mediums was determined at the same wavelengths previously mentioned against the pre-determined calibration curves for each AMX, AMP, and KAN drugs using the UV spectrophotometer. The obtained data were used for assessing cumulative release and mathematical modeling of release mechanisms.

\subsection{Application of Drug Release Data to Mathematical Models}

The application of drug release data to mathematical models is usually a few mathematical equations that define the dissolution profile. Once a suitable function has been selected, an assessment of the dissolution profile can be performed, and the drug release profile can be correlated with drug release kinetic models.

\subsubsection{Zero Order Kinetics}

Zero order kinetics describe the process of continuous drug release from a drug delivery system, and the level of the drug in the blood remains constant throughout the drug release. Hence, the drug release kinetics from an in vitro release study are plotted against time to study the data. In this kinetic model, the drug release rate is independent of its concentration. Used zero order equation (Equation (5)) is [32]:

$$
\mathrm{C}_{\mathrm{t}}=\mathrm{C}_{0}+\mathrm{K}_{0} \mathrm{t}
$$

In the equation, $C_{t}$ shows the amount of drug released in a given time, $C_{0}$ is the initial concentration of the drug, and $\mathrm{K}_{0}$ is the zero order rate constant.

\subsubsection{First Order Kinetics}

First order kinetics describe a concentration-dependent drug release rate from the delivery system. The used first order equation (Equation (6)) is [32]:

$$
\mathrm{dC} / \mathrm{dt}=\mathrm{K}_{1}\left(\mathrm{C}_{\mathrm{t}}-\mathrm{C}_{0}\right)
$$

In the Equation (6), $\mathrm{dC} / \mathrm{dt}$ shows the rate of change in concentration with respect to time, and $K_{1}$ represents the first order rate constant expressed in units of time $(t)$. 


\subsubsection{Higuchi Model}

The Higuchi model describes the release of drugs from the insoluble matrix as a square root of a time-dependent process based on Fickian diffusion. The used Higuchi equation (Equation (7)) is [32]:

$$
\mathrm{Q}=\mathrm{K}_{\mathrm{H}} \mathrm{t}^{1 / 2}
$$

In the Equation (7), $Q$ represents the cumulative amount of drug released at the time (t per unit area), $\mathrm{K}_{\mathrm{H}}$ shows the Higuchi dissolution constant.

\subsubsection{Korsmeyer-Peppas Model}

In order to understand the mechanism of drug diffusion from patches, release data were detected using the well-known empirical equation proposed by Korsmeyer and Peppas. The Korsmeyer-Peppas model describes the drug release mechanism from a polymeric system. The used Korsmeyer-Peppas equation (Equation (8)) is [33]:

$$
\mathrm{M}_{\mathrm{t}} / \mathrm{M} \infty=\mathrm{K}_{\mathrm{kp}} \mathrm{t}^{n}
$$

In the Equation (8), $\mathrm{M}_{\mathrm{t}}$ represents the amount of drug released at time $\mathrm{t}, \mathrm{M} \infty$ shows the amount of drug released after $\infty$ period, $n$ symbolize the release exponent, and $\mathrm{K}_{\mathrm{kp}}$ depicts the Korsmeyer-Peppas release rate constant.

For a cylindrical geometry with a non-swellable drug release system, when $\mathrm{n}=0.45$, the drug release mechanism is Fickian diffusion, when $n=1$, Case II transport occurs leading to the zero-order release and when the value of $\mathrm{n}$ is between 0.45 and 1 , NonFickian diffusion occurs [33].

\subsection{Antibacterial Activity Assay}

The inhibition method zone was used to investigate the antibacterial activity of the drug patches against Gram-positive (S. aureus) and Gram-negative (E. coli) bacterial strains as the model organisms. The bacterial cultures from different individual colonies were cultivated in Luria-Bertani (LB) broth $(10 \mathrm{~g} / \mathrm{L}$ bacto-tryptone, $5 \mathrm{~g} / \mathrm{L}$ yeast extract, $5 \mathrm{~g} / \mathrm{L}$ $\mathrm{NaCl}$ ) overnight at $37^{\circ} \mathrm{C}$. The bacterial strains (107 colony-forming unit $(\mathrm{cfu}) / \mathrm{mL}$ ) were inoculated on LB-agar (LB broth with $15 \mathrm{~g} / \mathrm{L}$ agar) plate using sterile cotton swabs. The equal weight of the patches was gently placed on the bacteria inoculated agar plates and incubated at $37^{\circ} \mathrm{C}$ for $24 \mathrm{~h}$. Zones of inhibition of the patches were evaluated by measuring the clear area that formed around each patch. Experiments were repeated in triplicate, and the average diameter of zones of inhibition was measured.

\section{Results and Discussion}

\subsection{Characterization of Fabricated Samples}

The EHD systems are governed by processing parameters and the properties of the working polymer solution [34]. EHD-3D printing is a single-step production process that provides both nano and micro-scale writing and combines the electrohydrodynamic atomization and 3D writing methods. All of the properties of the working polymer solution, including viscosity, electrical conductivity, density, and surface tension, are given in Table 1. The presence of the drugs in the resulting patches did not cause any significant influence on the physical properties of the BC/PCL solutions.

\begin{tabular}{|c|c|c|c|c|}
\hline $\begin{array}{l}\text { Sample Name } \\
\text { (wt. ratio) }\end{array}$ & $\begin{array}{c}\text { Viscosity } \\
\text { (Pa.S) }\end{array}$ & $\begin{array}{c}\text { Electrical } \\
\text { Conductivity } \\
\left(\mu . S \mathrm{~cm}^{-1}\right)\end{array}$ & $\begin{array}{c}\text { Density } \\
\left(\mathrm{kg} \mathrm{m}^{-3}\right)\end{array}$ & $\begin{array}{c}\text { Surface } \\
\text { Tension } \\
\left(\mathrm{mN} \mathrm{m}^{-1}\right)\end{array}$ \\
\hline BC /PCL (5:95) & $363 \pm 0.5$ & $1.20 \pm 0.03$ & $1445 \pm 2$ & $52.8 \pm 0.1$ \\
\hline $\mathrm{BC} / \mathrm{PCL}(5: 95)+\mathrm{AMX}$ & $368 \pm 0.3$ & $1.20 \pm 0.02$ & $1448 \pm 1$ & $52.9 \pm 0.1$ \\
\hline BC/PCL (5:95) +AMP & $371 \pm 0.1$ & $1.20 \pm 0.02$ & $1452 \pm 1$ & $53.2 \pm 0.5$ \\
\hline $\mathrm{BC} / \mathrm{PCL}(5: 95)+\mathrm{KAN}$ & $376 \pm 0.2$ & $1.20 \pm 0.01$ & $1459 \pm 1$ & $53.4 \pm 0.3$ \\
\hline
\end{tabular}

Table 1. Physical properties of EHD-3D printed solutions. (Mean \pm SD, $n=3$ ). 
As stated previously [23], the EHD-3D printing process could be influenced by the concentration of the printed solution and the electric field strength. In this study, the diameters of resultant fibers changed with variant PCL solution concentration values under $1.5 \mathrm{kV}$, and $10 \mathrm{wt} . \%$ PCL found to be the best sample with $100 \pm 5 \mu \mathrm{m}$ mean fiber diameter (Figure 2A). Additionally, different voltage values from 1 to $6 \mathrm{kV}$ were applied for detecting the optimal fiber structure of $10 \mathrm{wt} . \%$ PCL (Figure 2B). Consequently, $1.5 \mathrm{kV}$ was found to be the optimal value for EHD-3D printing of $10 \mathrm{wt} . \%$ PCL solution. In another preliminary study [30], different ratios of BC $(3,5,7,10$, and $12 \mathrm{wt} . \%)$ were mixed with $10 \mathrm{wt} . \%$ PCL to produce layer-on-layer stacked patches. According to optical microscopy images, the 5:95 (wt. ratio) BC/PCL solution sample showed the best fiber structure and inter-fibrous pore size with $100 \times 100 \mu^{2}$ (Figure 2C). Therefore, BC/PCL 5:95 (wt. ratio) blend solution was selected to carry AMX, AMP, and KAN antibiotics for further research made in this study.

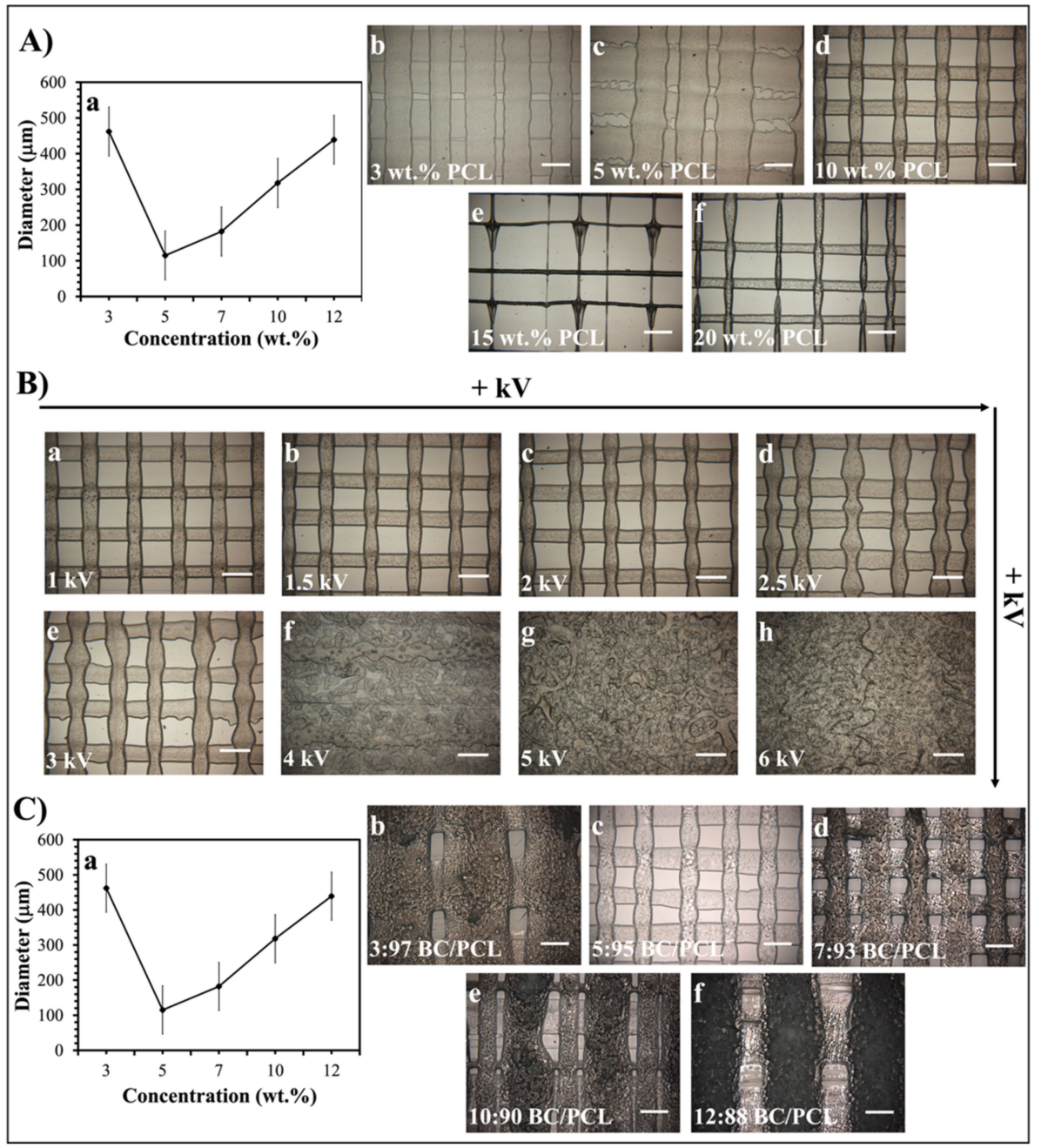

Figure 2. (A) EHD-3D printed fiber diameter graph (a) using different concentrations of PCL solution and optical images of the patches $(\mathrm{b}-\mathrm{f})$. (B) Optical images of the various voltage value $(1-6 \mathrm{kV})$ applied EHD-3D printed deposited fibers of $10 \mathrm{wt} . \%$ PCL with different alignments and structures. (C) EHD-3D printed fiber diameter graph (a) using different concentrations of BC/PCL composition and optic images of the samples (b-f). (All scale bars indicate $100 \mu \mathrm{m}$ ).

Microfibers in the antibiotic patches were pictured with SEM after being left in the vacuum oven and represented along with digital photographs of relevant samples in Figure 3. According to morphological observations on SEM and measurements in the ImageJ program, inter-fibrous pore sizes were $100 \times 100 \mu \mathrm{m}^{2}$ for BC/PCL (5:95 wt. ratio) and $\mathrm{BC} / \mathrm{PCL}+\mathrm{AMX}$ samples and sub-100 $\times 100 \mu \mathrm{m}^{2}$ for $\mathrm{BC} / \mathrm{PCL}+\mathrm{AMP}$ 
and $\mathrm{BC} / \mathrm{PCL}+\mathrm{KAN}$ samples, with mean fiber diameters of $50.1 \pm 0.7 \mu \mathrm{m}$ for $\mathrm{BC} / \mathrm{PCL}$, $77.1 \pm 4.8 \mu \mathrm{m}$ for BC/PCL+AMX, $86.3 \pm 45.8 \mu \mathrm{m}$ for BC/PCL+AMP, and $140.2 \pm 9.1 \mu \mathrm{m}$ for $\mathrm{BC} / \mathrm{PCL}+\mathrm{KAN}$, respectively.
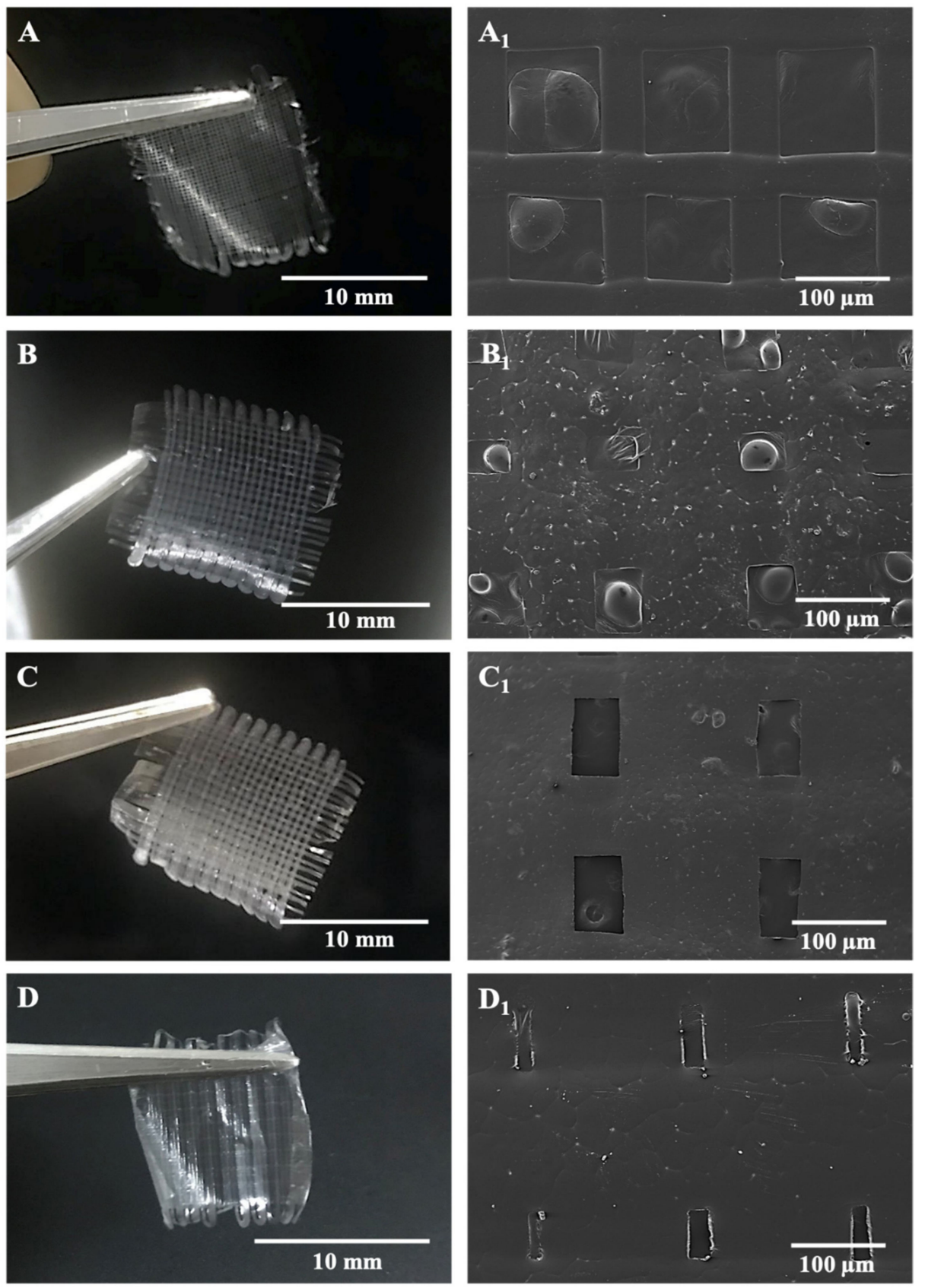

Figure 3. SEM images of EHD-3D printed patches with digital photographs of BC/PCL 5:95 (wt. ratio) patch with inter-fibrous pore size $100 \times 100 \mu \mathrm{m}^{2}\left(\mathbf{A}, \mathbf{A}_{\mathbf{1}}\right)$, AMX-loaded patch with inter-fibrous pore size $100 \times 100 \mu \mathrm{m}^{2}\left(\mathbf{B}, \mathbf{B}_{1}\right)$, AMP-loaded patch with inter-fibrous pore size sub-100 $\times 100 \mu \mathrm{m}^{2}$ $\left(\mathbf{C}, \mathbf{C}_{\mathbf{1}}\right)$ and KAN-loaded patch with inter-fibrous pore size sub-100 $\times 100 \mu \mathrm{m}^{2}\left(\mathbf{D}_{\mathbf{1}}, \mathbf{D}_{\mathbf{1}}\right)$.

The variation in fiber diameter can be explained due to the varied molecular weight difference caused by different drugs since high molecular weight promotes obtaining fibers with a larger diameter [35]. Thus, the EHD-3D printing yields thinner fibers when the molecular weight decreases. However, the AMP drug had more molecular weight than $\mathrm{AMX}$ and $\mathrm{BC} / \mathrm{PCL}+\mathrm{AMX}$ fibers were thinner in diameter than $\mathrm{BC} / \mathrm{PCL}+\mathrm{AMP}$ fibers. In this case, this phenomenon can be explained based on the chemical structure of the 
monomer unit of BC/PCL 5:95 (wt. ratio) and its chemical interaction with AMP antibiotic. Therefore, FTIR tests were performed to examine the presence and possible chemical interaction between polymers and antibiotics.

SEM images of patches revealed the interconnected pores on the microfibers. The rapid evaporation of DCM may have created a rise in local phase separation, and the solvent-rich regions may have transformed into pores during the process [36]. In this study, pore sizes were in the micro-range, and porosity varied with different types of antibiotics, as shown in Table 2. As a general rule, the pore size and porosity increase as a consequence of the addition of the antibiotics; the highest increase being recorded for the patches with AMX (highest pore size-10.20 $\pm 0.35 \mu \mathrm{m}^{2}$ ) and AMP (highest porosity-53.21 $\pm 1.76 \%$ ) during the patch with KAN exhibit the lowest increase.

Table 2. Pore size and porosity of EHD-3D printed patches. (Mean $\pm \mathrm{SD}, n=3$ ).

\begin{tabular}{ccc}
\hline Sample Name (wt. ratio) & Pore Size $\left(\boldsymbol{\mu \mathbf { m } ^ { 2 }}\right)$ & Porosity $(\%)$ \\
\hline BC/PCL (5:95) & $2.22 \pm 0.85$ & $11.52 \pm 1.14$ \\
BC/PCL (5:95) +AMX & $10.20 \pm 0.35$ & $32.43 \pm 1.36$ \\
BC/PCL (5:95) +AMP & $6.18 \pm 0.12$ & $53.21 \pm 1.76$ \\
BC/PCL (5:95) +KAN & $3.06 \pm 1.09$ & $19.11 \pm 1.44$ \\
\hline
\end{tabular}

Biomedical applications require highly porous patches that should mimic the biological environment they are intended to interact with to improve biocompatibility and allow increased drug loading capacity [37]. Biological environments usually have porous structures ranging from nano- to macroscale [38].

FTIR spectroscopy was used to confirm the possible interaction between antibiotics and polymers in produced patches. Figure 4 shows the FTIR absorbance spectra of BC/PCL 5:95 (wt. ratio), neat $\mathrm{AMX}, \mathrm{BC} / \mathrm{PCL}+\mathrm{AMX}$, neat $\mathrm{AMP}, \mathrm{BC} / \mathrm{PCL}+\mathrm{AMP}$, neat $\mathrm{KAN}$, and $\mathrm{BC} / \mathrm{PCL}+\mathrm{KAN}$ samples. Typical BC and PCL absorption bands were observed in all samples $[30,39]$. When the functional groups of the drug and the polymer interact chemically, FTIR spectra is expected to show band shifts and dilatations in the spectrum compared to the pure drug and polymer spectra [40]. No chemical binding between AMX and BC or PCL was observed when examining the AMX containing BC/PCL (5:95 weight ratio) patch. In addition, no chemical interaction between KAN and BC/PCL (5:95 weight ratio) was observed in the BC/PCL+KAN patch. AMX or KAN drugs were not chemically bound to the hydrogen bonds of BC or the carbonyl groups of PCL. They were physically bounded to the patches of the BC/PCL (5:95 weight ratio) blend. A physically bounded drug can be efficiently released from the patch. It is expected to have a faster release. Thus, a burst, such as a release, and high initial antimicrobial activity is expected [41].

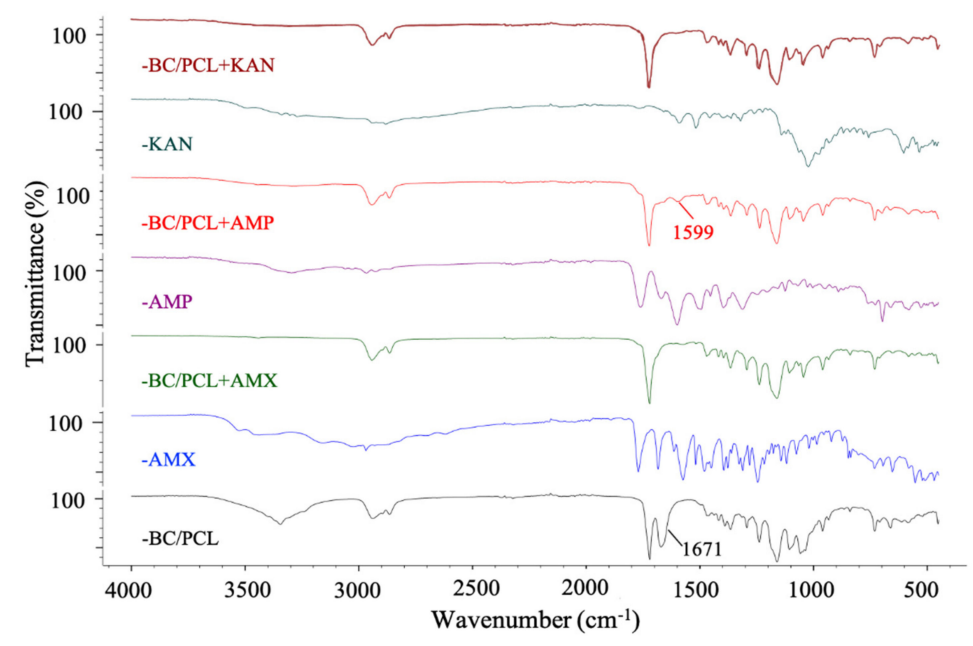

Figure 4. FTIR spectra of EHD-3D printed patches. 
On the other hand, the band of BC/PCL at $1671 \mathrm{~cm}^{-1}$ shifted to $1599 \mathrm{~cm}^{-1}$ in $\mathrm{BC} / \mathrm{PCL}+\mathrm{AMP}$ patch, and this chemical interaction can be the reason for the increased fiber diameter of the BC/PCL+AMP patch. Moreover, solution characteristics can also be the reason for this, even though the AMP has a higher molecular weight than AMX. This difference can be mainly associated with the chemical structure, AMP being a very soluble molecule, oligosaccharide $(\mathrm{Mw}=484.499 \mathrm{~g} / \mathrm{mol})$ with six free hydroxyl and four free amino groups, which can strongly interact via hydrogen bonds with the polymeric patch.

Mechanical properties of EHD-3D printed patches $(\mathrm{BC} / \mathrm{PCL}, \mathrm{BC} / \mathrm{PCL}+\mathrm{AMX}$, $\mathrm{BC} / \mathrm{PCL}+\mathrm{AMP}$, and $\mathrm{BC} / \mathrm{PCL}+\mathrm{KAN}$ ) were investigated using a tensile testing device, and relevant stress-strain curves for patches are represented in Figure 5. Ultimate tensile strength and Young's modulus of the BC/PCL patch were 5.64 and 9.72 MPa, respectively. AMX, AMP, and KAN loaded BC/PCL patches exhibited lower ultimate tensile strength $(3.87,3.38$, and $5.35 \mathrm{MPa}$, respectively) than the $\mathrm{BC} / \mathrm{PCL}$ patch. As stated previously [42], poor interface interaction and unstable phase dispersion can compromise the mechanical properties of polymer composite systems, which can be the reason behind the reduction in tensile strength with the addition of antibiotics to the BC/PCL blend. AMX, AMP, and KAN contain patches that also exhibited poor Young's modulus values $(7.58,5.61$, and $8.63 \mathrm{MPa}$, respectively) compared to the BC/PCL patch. As it is known, a decrease in Young's modulus results from an increase in the porosity of that material [43]. In this study, porosity values of AMX, AMP, and KAN loaded patches are found higher than the BC/PCL patch and this increase in porosity reduced Young's modulus values. The Young's modulus of the human soft tissues ranges from 0.6 to $1.7 \mathrm{MPa}$ [44]. Hence, it is thought that the produced drug patches can meet the mechanical requirements needed at various anatomical locations, such as the skin, muscle, or tissues where the drug needs to be delivered.
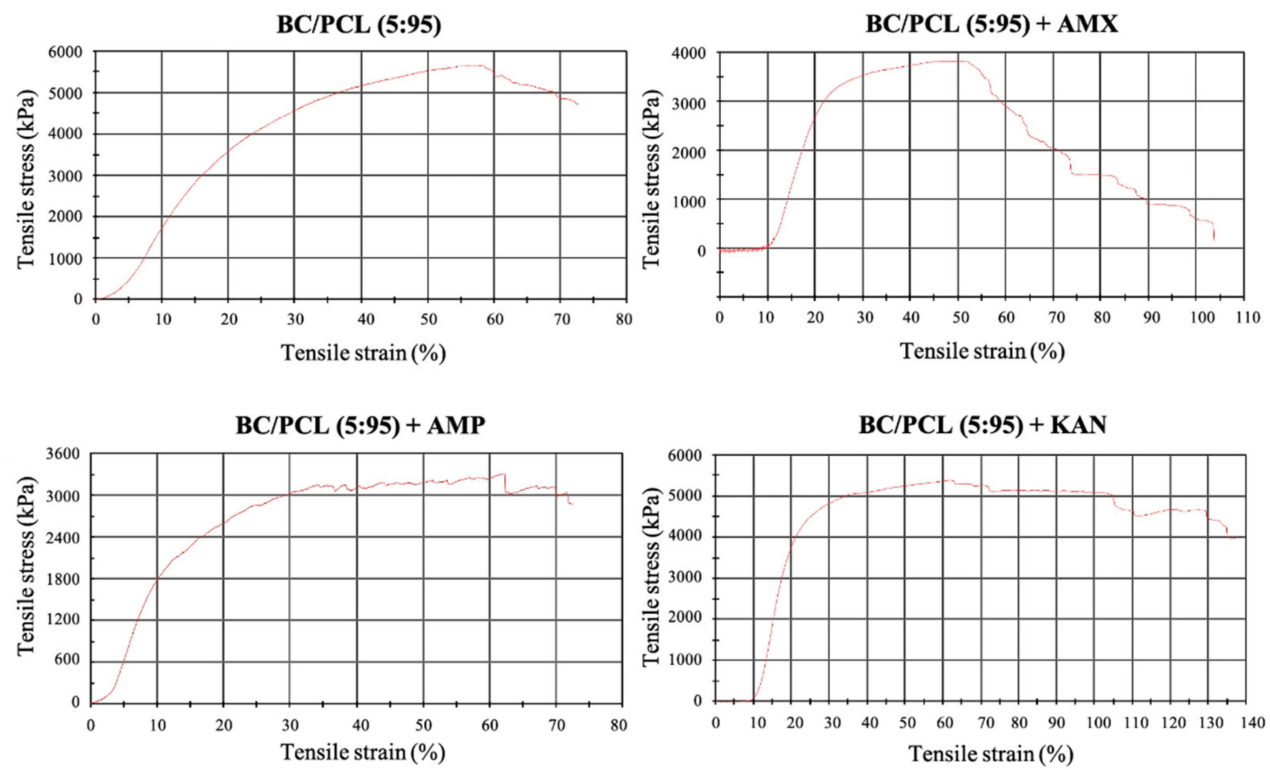

\begin{tabular}{ccc}
\hline Sample Name & Ultimate Tensile Strength (MPa) & Young's modulus (MPa) \\
\hline BC/PCL (5:95) & $5.64 \pm 0.04$ & $9.72 \pm 0.05$ \\
BC/PCL (5:95) + AMX & $3.87 \pm 0.03$ & $7.58 \pm 0.03$ \\
BC/PCL (5:95) + AMP & $3.38 \pm 0.02$ & $5.61 \pm 0.03$ \\
BC/PCL (5:95) + KAN & $5.35 \pm 0.03$ & $8.63 \pm 0.04$ \\
\hline
\end{tabular}

Figure 5. Stress-strain curves of EHD-3D printed patches with ultimate tensile strength and Young's modulus values. 
Since swelling properties of a scaffold are vital because of its role in enabling liquid absorption of physiological secretions and allow the efficient exchange of nutrients and waste of regenerated tissue [34], the neat and the drug-containing patches were further characterized to determine their swelling behavior after submersion in the phosphate buffer saline (PBS, $\mathrm{pH}=7.4$ ) at $37^{\circ} \mathrm{C}$ for $24 \mathrm{~h}$. At the end of $24 \mathrm{~h}$ of immersions, the degree of swelling of the BC/PCL patch $(168 \%)$ was comparable with those of the patches loaded with antibiotics: AMX loaded patch $\approx 162 \%$, AMP loaded patch $\approx 159 \%$, and KAN loaded patch $\approx 164 \%$ (Figure 6 ). Considering a release rate of about $30-35 \%$ of the antibiotics, it can assume that the presence of antibiotics increases the swelling ratio because of the additional porosity assured after the antibiotic release. The swelling and water uptake depends on the hydrophobicity of the polymer [45], as it is well-known that the PCL is a hydrophobic polyester and can prevent water uptake [46]. Besides, since BC is a hydrophilic polymer, it can pick the water that diffuses into the PCL matrix while increasing the equilibrium swelling of the water [47].

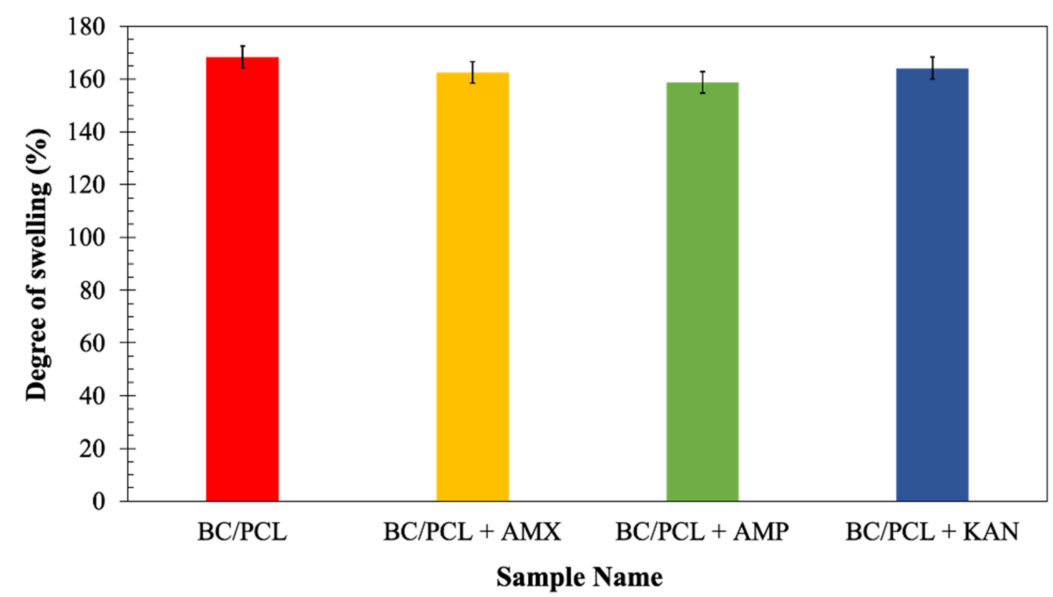

Figure 6. The degree of swelling (\%) of EHD-3D printed patches.

Antibiotic addition to the BC/PCL blend in the selected quantities did not interfere with patch water uptake capability. Consequently, produced patches can prevent loss of body fluid and nutrients due to the enhanced swelling ability while releasing their loaded drugs.

The yield percentage, drug loading, and antibiotic encapsulation efficiency of the patches are presented in Table 3. The drug loading was similar for the three different antibiotics $(21 \%)$, while the encapsulation efficiency of the drugs was similar for the three different antibiotics and between $96 \%$ and $98 \%$.

Table 3. Yield percentage, drug loading, and encapsulation efficiency of the patches. (Mean \pm SD, $n=3)$.

\begin{tabular}{cccc}
\hline $\begin{array}{c}\text { Sample Name } \\
\text { (wt. ratio) }\end{array}$ & $\begin{array}{c}\text { Yield } \\
\mathbf{( \% )}\end{array}$ & $\begin{array}{c}\text { Drug Loading } \\
\text { (\%) }\end{array}$ & $\begin{array}{c}\text { Encapsulation Efficiency } \\
\text { (\%) }\end{array}$ \\
\hline BC/PCL (5:95) & $98.4 \pm 0.6$ & - & - \\
BC/PCL (5:95) +AMX & $98.2 \pm 1.3$ & $21.9 \pm 0.3$ & $97.4 \pm 0.9$ \\
BC/PCL (5:95) +AMP & $96.3 \pm 2.1$ & $21.7 \pm 0.7$ & $96.8 \pm 1.6$ \\
BC/PCL (5:95) +KAN & $97.9 \pm 1.9$ & $21.9 \pm 0.5$ & $98.6 \pm 1.4$ \\
\hline
\end{tabular}

\subsection{Drug Release and Mathematical Modeling of Release Mechanisms}

Measurement of drug release from the patches was performed using the UV spectroscopy method. For this purpose, AMX, AMP, and KAN calibration curves were prepared to determine release kinetics (Figure 7). 

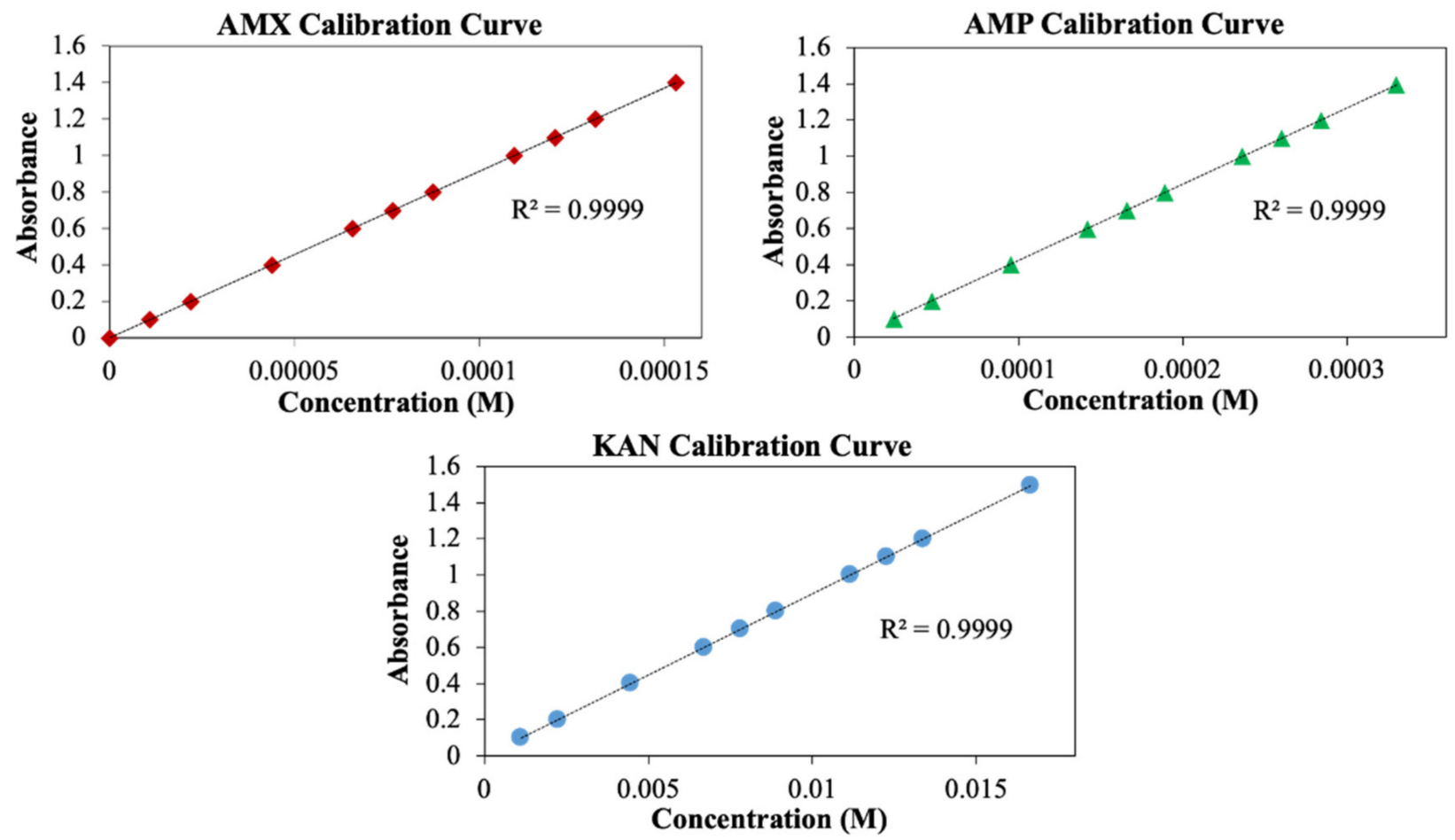

Figure 7. Calibration curves for AMX, AMP, and KAN drugs.

It is crucial to investigate drug release profiles for several days due to the advantages of increasing medication and drug efficacy, reducing side effects, and reducing the frequency of administration of these drugs [48]. In this study, the release of AMX, AMP, and KAN drugs from EHD-3D printed patches were examined for 14 days $(336 \mathrm{~h})$ in PBS, $\mathrm{pH} 7.4$ (Figure 8).

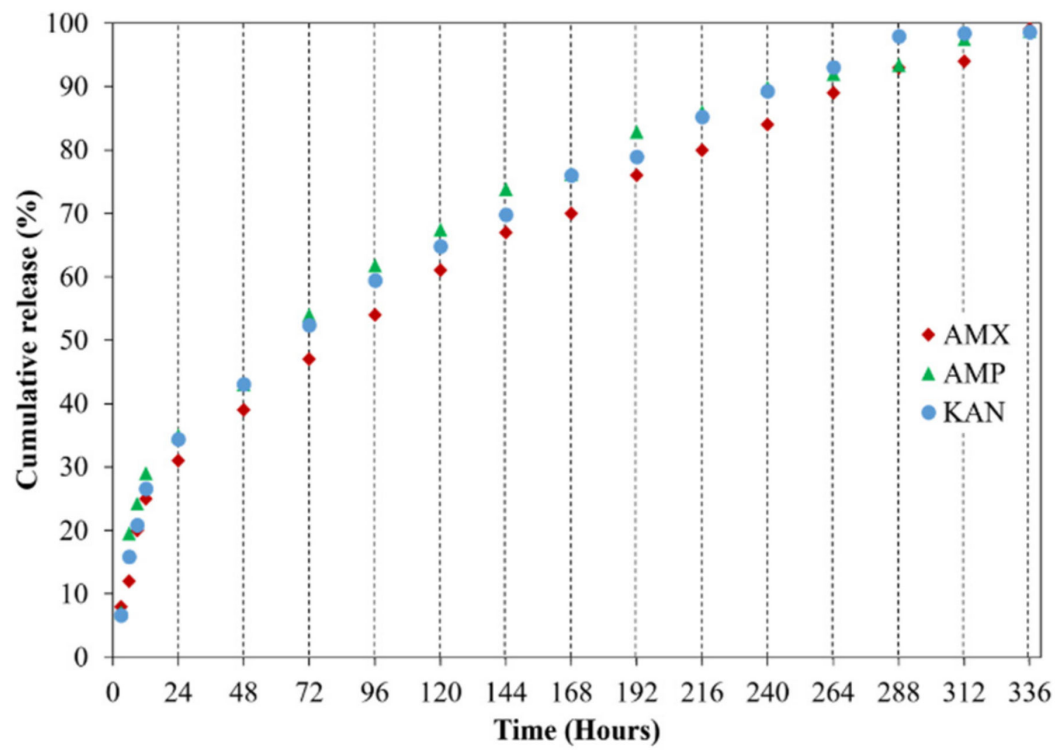

Figure 8. Cumulative release (\%) of loaded antibiotic patches.

All release curves mainly consisted of two phases as the first phase, a "burst release", and then "slow-release", so that the second phase took place. The initial burst release is beneficial for releasing antibiotic drugs since it is essential to remove the spreading bacteria before they start to multiply [49]. Hence, to prevent the remaining population for several organisms that survive the first immediate release, followed by a sustained release 
of antibiotics is required [50]. After the burst release phase, increases were observed in the release of drugs due to the concentration of AMX, AMP, and KAN in the patches, and then these increases were found to be linear and prolonged over many days. The AMX loaded patch showed $99.1 \pm 0.6 \%$ cumulative release after $336 \mathrm{~h}$, whereas the cumulative release of AMP was about $98.1 \pm 0.3 \%$ after $336 \mathrm{~h}$. The cumulative release of KAN was $98.6 \pm 0.6 \%$ after $336 \mathrm{~h}$ of release studies. The increased surface area for the release of the drugs can be responsible for improving the release of the drugs when formulated as microfibers [51].

Wang et al. [52] produced antibiotically loaded (tetracycline hydrochloride) patches using polycaprolactone (PCL), polyvinyl pyrrolidone (PVP), and their composite system (PVP-PCL) by the EHD-3D printing method. The researchers examined the release of antibiotic drug from PCL-PVP dosage forms for 5 days. They witnessed a slower antibiotic release compared to neat PCL or PVP. It was observed that the size of gaps between the fibers in the printed patches influenced the release of the antibiotic material. As a result of this study, it was found that the EHD-3D printing method is a promising method for adapting the dosage forms with minimum adjuvants and large-scale procedures.

The release curves were also subjected to model fitting consisting of various models such as zero order, first order, Higuchi, and Korsmeyer-Peppas models (Figures 9-11). Graphical representations of the cumulative percentage of drug release against time showed that the release of AMX, AMP, and KAN from the patches correctly followed the Higuchi model. Drug release profiles were very close to the trend line or regression line and had the highest coefficient value $\left(\mathrm{R}^{2}\right)$ for AMX, AMP, and KAN loaded patches $(0.9961,0.9761$, and 0.9888 , respectively).

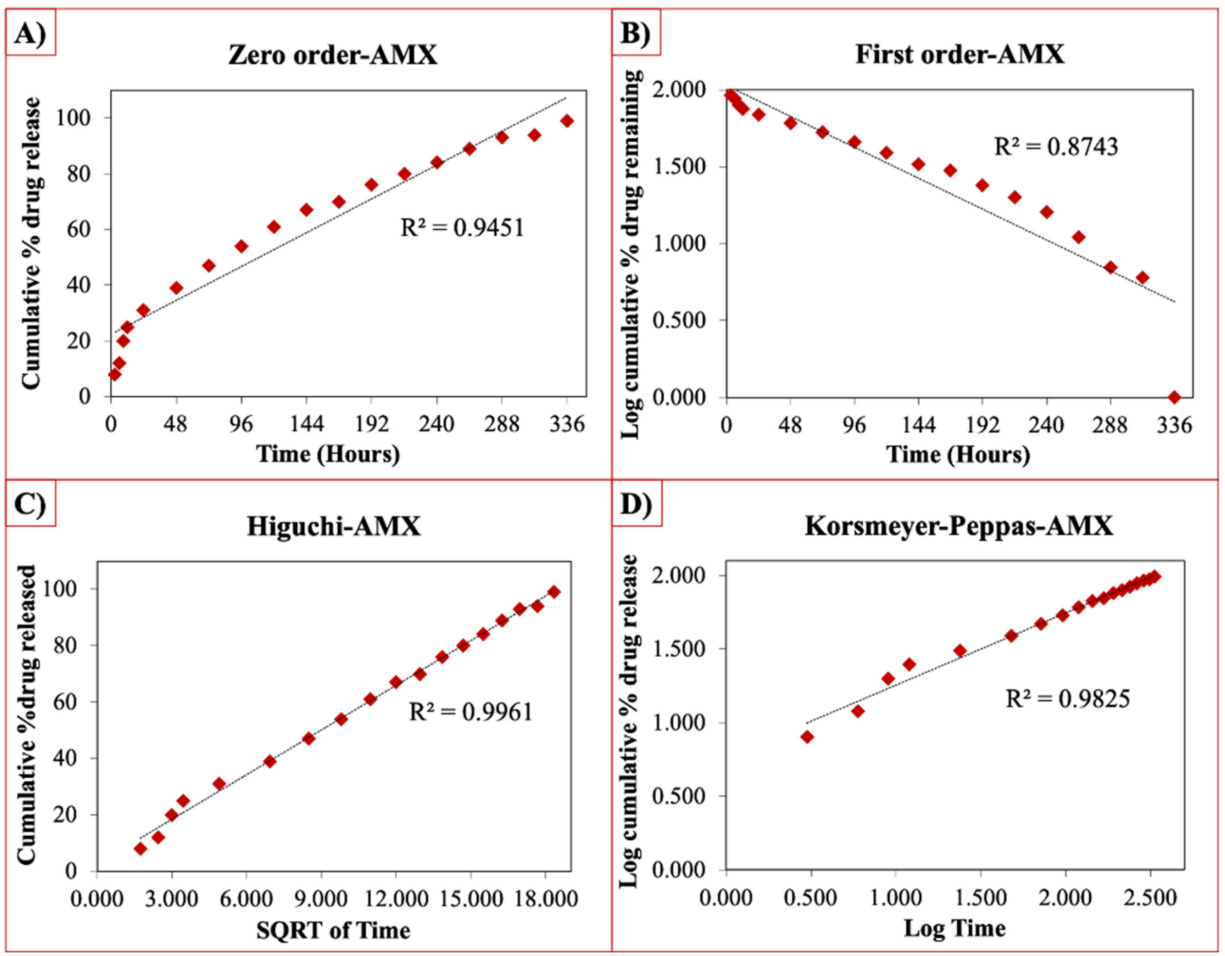

Figure 9. Zero order (A), first order (B), Higuchi (C), Korsmeyer-Peppas (D) kinetic releases of $\mathrm{BC} / \mathrm{PCL}+\mathrm{AMX}$ patch. 

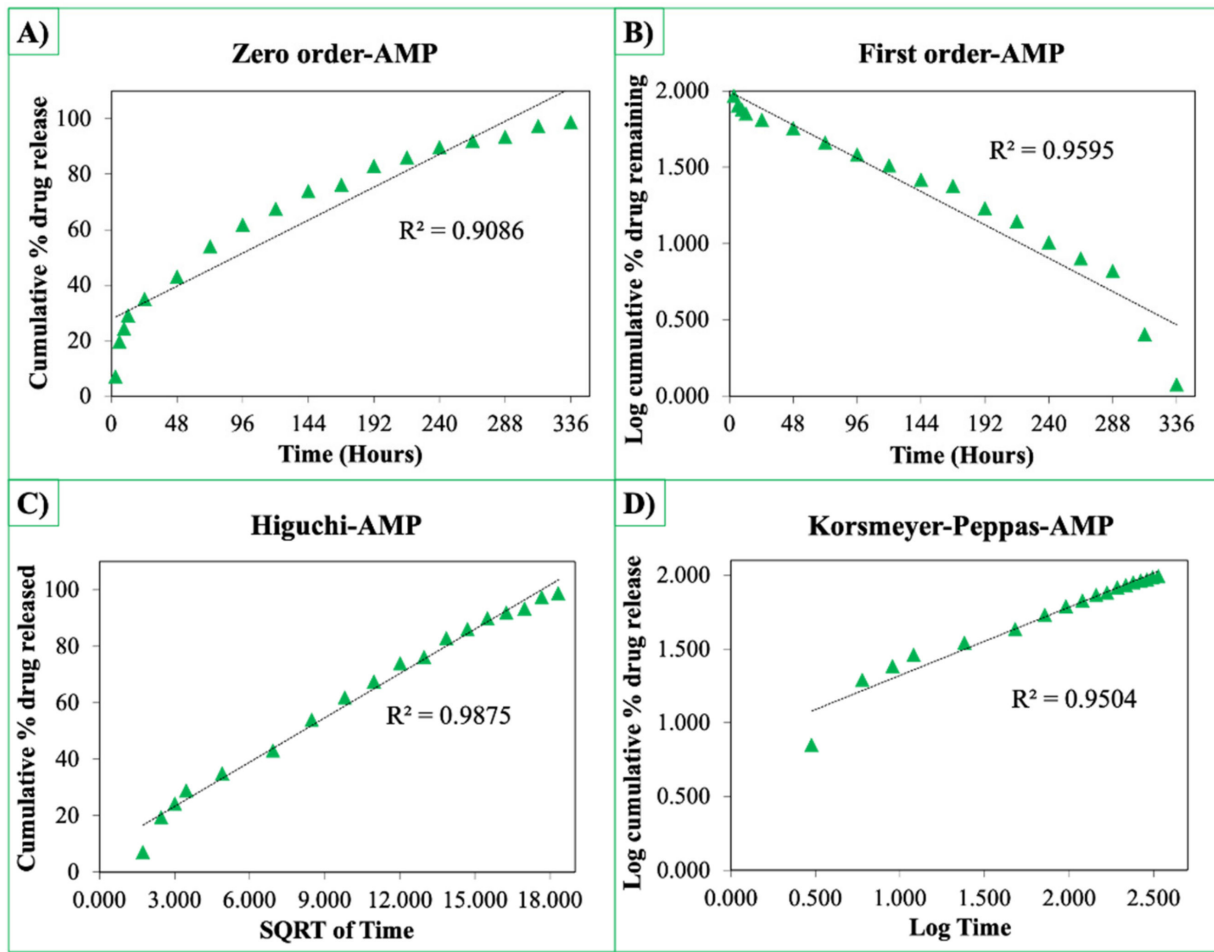

Figure 10. Zero order (A), first order (B), Higuchi (C), Korsmeyer-Peppas (D) kinetic releases of $\mathrm{BC} / \mathrm{PCL}+\mathrm{AMP}$ patch.
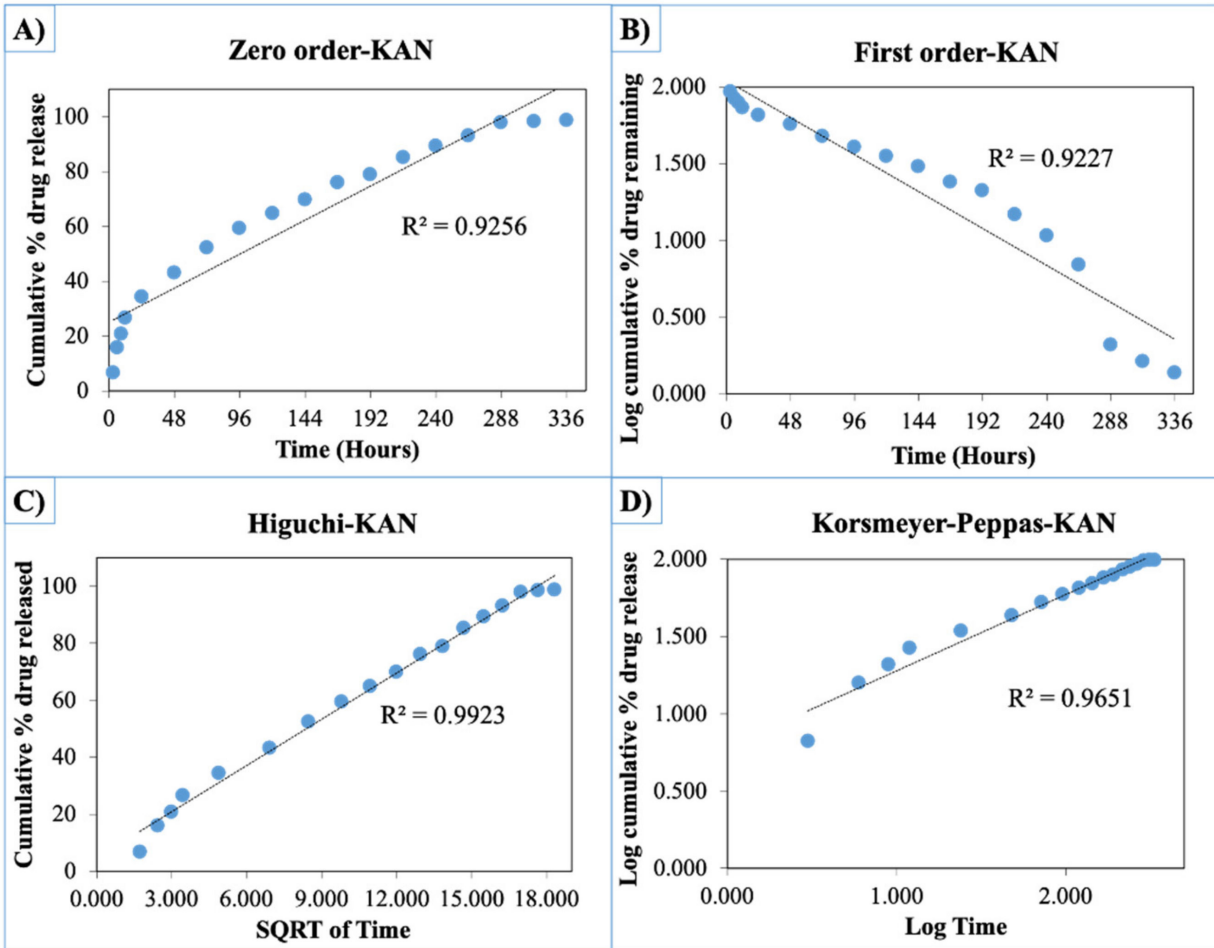

Figure 11. Zero order (A), first order (B), Higuchi (C), Korsmeyer-Peppas (D) kinetic releases of $\mathrm{BC} / \mathrm{PCL}+\mathrm{KAN}$ patch.

The Korsmeyer-Peppas model was applied to release profiles to determine the diffusion types. After the Korsmeyer-Peppas model application, the diffusional exponent, which is indicative of the release mechanism (n), was found for all samples. The $n=0.45$ 
value indicates Fickian diffusion, while values between 0.45 and 1.00 suggest non-Fickian transport and values higher than 1.00 suggest zero order/case II transport of a drug [53].

The diffusion exponent ' $\mathrm{n}$ ' was $0.49,0.46$, and 0.48 for AMX, AMP, and KAN loaded patches, respectively. The ' $n$ ' values for AMX, AMP, and KAN loaded patches indicated that the releases of the drugs followed Fick's law of diffusion. As a general conclusion, regardless of the solubility of the antibiotic, the release of the drugs from patches was likely to be controlled by a diffusion mechanism [54].

\subsection{Antibacterial Assessment of Fabricated Patches}

The antibacterial potentials of the patches were evaluated as the diameter of the zone around the 3D printed scaffolds. The experiment was performed in triplicate, and the average of the zones of inhibition used to determine the antibacterial activity.

Table 4 shows the inhibition zones after $24 \mathrm{~h}$ of incubation. The inhibition zones were observed as a clear circular area surrounding the samples specifying the zone of bacteria that was destroyed or prevented from growing. BC/PCL was used as a negative control and did not have any antibacterial properties, as they showed no activity against the two bacterial strains (S. aureus and E. coli). According to the results in Table 4, BC/PCL+AMX, $\mathrm{BC} / \mathrm{PCL}+\mathrm{AMP}$, and BC/PCL+KAN drug patches showed 43, 39, and $30 \mathrm{~mm}$ diameter inhibition zones against $S$. aureus, respectively. On the other hand, the same drug patches showed 35, 37, and $35 \mathrm{~mm}$ inhibition zones against E. coli, respectively. Results suggest that all three different antibiotics (AMX, AMP, and KAN) containing patches can be used as an effective antibacterial patch on both Gram-positive and Gram-negative bacteria.

Table 4. Antibacterial properties of the EHD-3D printed patches against S. aureus and E. coli bacteria. All scale bars indicate 10 mm.

\begin{tabular}{|c|c|c|c|c|}
\hline Bacterial Strain $\quad$ Sample & BC/PCL & BC/PCL+AMX & BC/PCL+AMP & BC/PCL+KAN \\
\hline S. aureus & & & & \\
\hline E. coli & & & & \\
\hline
\end{tabular}

\section{Conclusions}

Antibiotic patches composed of BC/PCL, AMX, AMP, and KAN, were prepared by the EHD-3D printing method, resulting in aligned layer-on-layer stacked fibers. The drug release properties and drug release kinetic models of different antibiotics loaded patches were evaluated. Drug-containing patches displayed micron-scaled fibers and inter-fibrous pore size. Moreover, microfibers exhibited a porous structure, which provided improved biocompatibility and increased drug loading capacity. All patches displayed enhanced swelling ability. They were found able to meet mechanical requirements needed at various anatomical locations according to tensile test results. The release of AMX, AMP, and KAN antibiotics from BC/PCL dosage forms was shown at 14 days (336 h). The kinetic models (zero order, first order, Higuchi, and Korsmeyer-Peppas) on drug release were profiled for each antibiotic patches. It was found that the release of the drugs from the patches followed Fick's law of diffusion. The antibacterial potential was evaluated, and 
AMX, AMP, and KAN were found effective on both Gram-positive and Gram-negative bacteria to provide antimicrobial activity to $\mathrm{BC} / \mathrm{PCL}$ patches. It is suggested that the single-step EHD-3D printing method offers rapidly tailored dosage forms with minimal excipients. Moreover, various types of antibiotics could be loaded and successfully released, regardless of their types, from produced BC/PCL patches. Produced antibiotic patches can meet the characteristic requirements needed in local transdermal applications with accelerated release characteristics, adjustability, and versatility for wound dressing studies, and decrease the pharmaceuticals industries' costs.

Author Contributions: Conceptualization, D.M.K. and O.G.; Data curation, E.A., E.Y., N.E., D.F. and G.D.; Formal analysis, E.A., E.Y., N.E. and G.D.; Investigation, G.D.; Methodology, E.A., E.Y. and N.E.; Project administration, O.G.; Supervision, D.M.K., D.F. and O.G.; Visualization, D.M.K., D.F. and A.F.; Writing—original draft, E.A., E.Y., N.E., D.F., G.D., A.F. and O.G.; Writing—review \& editing, D.M.K., A.F. and O.G. All authors have read and agreed to the published version of the manuscript.

Funding: The APC was funded by UPB.

Institutional Review Board Statement: Not applicable.

Informed Consent Statement: Not applicable.

Data Availability Statement: The raw/processed data required to reproduce these findings cannot be shared at this time due to technical or time limitations. Data will be made available on request.

Acknowledgments: This study was supported by BAPKO, Marmara University; project no: FEN-CYLP-110117-0021. D.M.K. would like to acknowledge UKIERI funding, project IND/CONT/G/1718/46 for collaborative work.

Conflicts of Interest: The authors declare no conflict of interest.

\section{References}

1. Negut, I.; Grumezescu, V.; Grumezescu, A.M. Treatment Strategies for Infected Wounds. Molecules 2018, $23,2392$. [CrossRef] [PubMed]

2. Misic, A.M.; Gardner, S.E.; Grice, E.A. The Wound Microbiome: Modern Approaches to Examining the Role of Microorganisms in Impaired Chronic Wound Healing. Adv. Wound Care 2014, 3, 502-510. [CrossRef] [PubMed]

3. Mathur, S.; Sutton, J. Personalized medicine could transform healthcare. Biomed. Rep. 2017, 7, 3-5. [CrossRef] [PubMed]

4. Ramasubbu, D.A.; Smith, V.; Hayden, F.; Cronin, P. Systemic antibiotics for treating malignant wounds. Cochrane Database Syst. Rev. 2017, 8, CD011609. [CrossRef] [PubMed]

5. Everts, R. How to Treat Wound Infection. Prevention and Treatment. 2016. Available online: https://www.acc.co.nz/assets/ provider/treating-wound-infections.pdf (accessed on 7 April 2020).

6. Smith, R.; Russo, J.; Fiegel, J.; Brogden, N. Antibiotic Delivery Strategies to Treat Skin Infections When Innate Antimicrobial Defense Fails. Antibiotics 2020, 9, 56. [CrossRef] [PubMed]

7. Langer, R. New methods of drug delivery. Science 1990, 249, 1527-1533. [CrossRef] [PubMed]

8. Saltzman, W.M. Drug Delivery-Engineering Principles for Drug Therapy; Oxford University Press: Oxford, UK, 2001.

9. Berchane, N.; Jebrail, F.; Andrews, M. Optimization of PLG microspheres for tailored drug release. Int. J. Pharm. 2010, 383, 81-88. [CrossRef]

10. Wei, L.; Cai, C.; Lin, J.; Chen, T. Dual-drug delivery system based on hydrogel/micelle composites. Biomaterials 2009, 30, 2606-2613. [CrossRef]

11. Ranganath, S.H.; Kee, I.; Krantz, W.B.; Chow, P.K.-H.; Wang, C.-H. Hydrogel Matrix Entrapping PLGA-Paclitaxel Microspheres: Drug Delivery with Near Zero-Order Release and Implantability Advantages for Malignant Brain Tumour Chemotherapy. Pharm. Res. 2009, 26, 2101-2114. [CrossRef]

12. Hoare, T.R.; Kohane, D.S. Hydrogels in drug delivery: Progress and challenges. Polymer 2008, 49, 1993-2007. [CrossRef]

13. Bhattacharyya, S.; Wang, H.; Ducheyne, P. Polymer-coated mesoporous silica nanoparticles for the controlled release of macromolecules. Acta Biomater. 2012, 8, 3429-3435. [CrossRef]

14. Akhtar, N.; Singh, V.; Yusuf, M.; Khan, R.A. Non-invasive drug delivery technology: Development and current status of transdermal drug delivery devices, techniques and biomedical applications. Biomed. Tech. Eng. 2020, 65, 243-272. [CrossRef]

15. Pastore, M.N.; Kalia, Y.N.; Horstmann, M.; Roberts, M.S. Transdermal patches: History, development and pharmacology. Br. J. Pharmacol. 2015, 172, 2179-2209. [CrossRef]

16. Jamróz, W.; Szafraniec, J.; Kurek, M.; Jachowicz, R. 3D Printing in Pharmaceutical and Medical Applications-Recent Achievements and Challenges. Pharm. Res. 2018, 35, 1-22. [CrossRef] 
17. Park, J.-U.; Lee, J.H.; Paik, U.; Lu, Y.; Rogers, J.A. Nanoscale Patterns of Oligonucleotides Formed by Electrohydrodynamic Jet Printing with Applications in Biosensing and Nanomaterials Assembly. Nano Lett. 2008, 8, 4210-4216. [CrossRef]

18. Huang, Y.; Bu, N.; Duan, Y.; Pan, Y.; Liu, H.; Yin, Z.; Xiong, Y. Electrohydrodynamic direct-writing. Nanoscale 2013, 5, 12007-12017. [CrossRef]

19. Meier, W. Polymer nanocapsules. Chem. Soc. Rev. 2000, 29, 295-303. [CrossRef]

20. Park, J.U. High-Resolution Electrohydrodynamic Jet Printing Methods for Applications in Electronics and Biotechnology. Ph.D. Thesis, University of Illinois at Urbana-Champaign, Champaign, IL, USA, 2009.

21. Wang, K.; Cai, L.; Zhang, L.; Dong, J.; Wang, S. Biodegradable Photo-Crosslinked Polymer Substrates with Concentric Microgrooves for Regulating MC3T3-E1 Cell Behavior. Adv. Heal. Mater. 2012, 1, 292-301. [CrossRef]

22. Ahn, S.H.; Lee, H.J.; Kim, G.H. Polycaprolactone Scaffolds Fabricated with an Advanced Electrohydrodynamic Direct-Printing Method for Bone Tissue Regeneration. Biomacromolecules 2011, 12, 4256-4263. [CrossRef]

23. Altun, E.; Akyol, S.; Ekren, N.; Kilic, O.; Gündüz, O.; Kılıç, O. Electrohydrodynamic (EHD) Bioprinting of Polycaprolactone Scaffolds. Mater. Sci. Forum 2018, 923, 93-97. [CrossRef]

24. Béduneau, A.; Saulnier, P.; Anton, N.; Hindré, F.; Passirani, C.; Rajerison, H.; Noiret, N.; Benoit, J.-P. Pegylated Nanocapsules Produced by an Organic Solvent-Free Method: Evaluation of their Stealth Properties. Pharm. Res. 2006, 23, 2190-2199. [CrossRef]

25. Albrecht, L.D.; Sawyer, S.W.; Soman, P. Developing 3D Scaffolds in the Field of Tissue Engineering to Treat Complex Bone Defects. 3D Print. Addit. Manuf. 2016, 3, 106-112. [CrossRef]

26. Bernards, D.A.; Lance, K.D.; Ciaccio, N.A.; Desai, T.A. Nanostructured Thin Film Polymer Devices for Constant-Rate Protein Delivery. Nano Lett. 2012, 12, 5355-5361. [CrossRef]

27. Altun, E.; Aydogdu, M.O.; Koc, F.; Crabbe-Mann, M.; Brako, F.; Kaur-Matharu, R.; Ozen, G.; Kuruca, S.E.; Edirisinghe, U.; Gunduz, O.; et al. Novel Making of Bacterial Cellulose Blended Polymeric Fiber Bandages. Macromol. Mater. Eng. 2018, 303, 1700607. [CrossRef]

28. Shah, N.; Ul-Islam, M.; Khattak, W.A.; Park, J.K. Overview of bacterial cellulose composites: A multipurpose advanced material. Carbohydr. Polym. 2013, 98, 1585-1598. [CrossRef]

29. Qiu, Y.; Qiu, L.; Cui, J.; Wei, Q. Bacterial cellulose and bacterial cellulose-vaccarin membranes for wound healing. Mater. Sci. Eng. C 2016, 59, 303-309. [CrossRef]

30. Altun, E.; Ekren, N.; Kuruca, S.E.; Gunduz, O. Cell studies on Electrohydrodynamic (EHD)-3D-bioprinted Bacterial Cellulose $\backslash$ Polycaprolactone scaffolds for tissue engineering. Mater. Lett. 2019, 234, 163-167. [CrossRef]

31. Puppi, D.; Piras, A.M.; Detta, N.; Dinucci, D.; Chiellini, F. Poly(lactic-co-glycolic acid) electrospun fibrous meshes for the controlled release of retinoic acid. Acta Biomater. 2010, 6, 1258-1268. [CrossRef] [PubMed]

32. Samuelov, Y.; Donbrow, M.; Friedman, M. Sustained Release of Drugs from Ethylcellulose-Polyethylene Glycol Films and Kinetics of Drug Release. J. Pharm. Sci. 1979, 68, 325-329. [CrossRef] [PubMed]

33. Ritger, P.L.; Peppas, N.A. A simple equation for description of solute release I. Fickian and non-fickian release from non-swellable devices in the form of slabs, spheres, cylinders or discs. J. Control. Release 1987, 5, 23-36. [CrossRef]

34. Aydogdu, M.O.; Altun, E.; Crabbe-Mann, M.; Brako, F.; Koç, F.; Ozen, G.; Kuruca, S.E.; Edirisinghe, U.; Luo, C.; Gündüz, O.; et al. Cellular interactions with bacterial cellulose: Polycaprolactone nanofibrous scaffolds produced by a portable electrohydrodynamic gun for point-of-need wound dressing. Int. Wound J. 2018, 15, 789-797. [CrossRef]

35. Roldán, G.J.C.; Bolivariana, U.P.; Martínez, Y.Q.; Gómez, L.M.A.; Vinasco, L.F.R.; Palacio, L.M.H. Influence of the molecular weight of polymer, solvents and operational condition in the electrospinning of polycaprolactone. Revista Facultad de Ingeniería Universidad de Antioquia 2017, 84, 35-45. [CrossRef]

36. Celebioglu, A.; Uyar, T. Electrospun porous cellulose acetate fibers from volatile solvent mixture. Mater. Lett. 2011, 65, 2291-2294. [CrossRef]

37. Wendorff, J.H.; Agarwal, S.; Greiner, A. Medicinal Applications for Electrospun Nanofibers. Electrospinning; Wiley-VCH Verlag GmbH \& Co. KGaA: Weinheim, Germany, 2012; pp. 217-236.

38. Currey, J.D. Biomechanics of Mineralized Skeletons. In Skeletal Biomineralization: Patterns, Processes and Evolutionary Trends; Carter, J.G., Ed.; Wiley: Hoboken, NJ, US, 2013.

39. Elzein, T.; Nasser-Eddine, M.; Delaite, C.; Bistac, S.; Dumas, P. FTIR study of polycaprolactone chain organization at interfaces. J. Colloid Interface Sci. 2004, 273, 381-387. [CrossRef]

40. Silverstein, R.M.; Bassler, G.C.; Morril, T.C. Spectrometric Identification of Organic Compounds; Wiley: New York, NY, USA, 1991.

41. Altun, E.; Aydogdu, M.O.; Koc, F.; Kutlu, O.; Gozuacik, D.; Yucel, S.; Gunduz, O. Amoxicillin Loaded Hollow Microparticles in the Treatment of Osteomyelitis Disease Using Single-Nozzle Electrospinning. BioNanoScience 2018, 8, 790-801. [CrossRef]

42. Wang, J.-C.; Chang, M.-W.; Ahmad, Z.; Li, J.-S. Fabrication of patterned polymer-antibiotic composite fibers via electrohydrodynamic (EHD) printing. J. Drug Deliv. Sci. Technol. 2016, 35, 114-123. [CrossRef]

43. Niinomi, M.; Hattori, T.; Niwa, S.; Yaszemski, M.; Trantolo, D.; Lewandrowski, K.-U.; Hasirci, V.; Altobelli, D.; Wise, D. Material Characteristics and Biocompatibility of Low Rigidity Titanium Alloys for Biomedical Applications. In Biomaterials in Orthopedics; Yaszemski, M., Trantolo, D., Lewandrowski, K., Hasirci, V., Altobelli, D., Wise, D., Eds.; Marcel Dekker, INC.: Basel, Switzerland, 2004; pp. 41-62.

44. Griffin, M.; Premakumar, Y.; Seifalian, A.; Butler, P.E.; Szarko, M. Biomechanical Characterization of Human Soft Tissues Using Indentation and Tensile Testing. J. Vis. Exp. 2016, 118, e54872. [CrossRef] 
45. Rodríguez-Galán, A.; Franco, L.; Puiggalí, J.; García, M.L.F. Biodegradable Polyurethanes and Poly(ester amide)s. In Handbook of Biodegradable Polymers: Isolation, Synthesis, Characterization and Applications; Lendlein, A., Sisson, A., Eds.; Wiley: Hoboken, NJ, USA, 2011; Chapter 6; pp. 133-154.

46. Dash, T.K.; Konkimalla, V.B. Poly-e-caprolactone based formulations for drug delivery and tissue engineering: A review. J. Control. Release 2012, 158, 15-33. [CrossRef]

47. Altun, E.; Aydogdu, M.O.; Togay, S.O.; Sengil, A.Z.; Ekren, N.; Haskoylu, M.E.; Oner, E.T.; Altuncu, N.A.; Ozturk, G.; CrabbeMann, M.; et al. Bioinspired scaffold induced regeneration of neural tissue. Eur. Polym. J. 2019, 114, 98-108. [CrossRef]

48. Valarezo, E.; Tammaro, L.; González, S.; Malagón, O.; Vittoria, V. Fabrication and sustained release properties of poly(عcaprolactone) electrospun fibers loaded with layered double hydroxide nanoparticles intercalated with amoxicillin. Appl. Clay Sci. 2013, 72, 104-109. [CrossRef]

49. Gimeno, M.; Pinczowski, P.; Pérez, M.; Giorello, A.; Martínez, M.Á.; Santamaría, J.; Arruebo, M.; Luján, L. A controlled antibiotic release system to prevent orthopedic-implant associated infections: An in vitro study. Eur. J. Pharm. Biopharm. 2015, 96, 264-271. [CrossRef]

50. Shin, Y.M.; Hohman, M.M.; Brenner, M.P.; Rutledge, G.C. Electrospinning: A whipping fluid jet generates submicron polymer fibers. Appl. Phys. Lett. 2001, 78, 1149-1151. [CrossRef]

51. Chou, S.-F.; Carson, D.; Woodrow, K.A. Current strategies for sustaining drug release from electrospun nanofibers. J. Control. Release 2015, 220, 584-591. [CrossRef]

52. Wang, J.-C.; Zheng, H.; Chang, M.-W.; Ahmad, Z.; Li, J.-S. Preparation of active 3D film patches via aligned fiber electrohydrodynamic (EHD) printing. Sci. Rep. 2017, 7. [CrossRef]

53. Peppas, N.A.; Duncan, R.; Wnek, G.E.; Hoffman, A.S.; Gao, G.H.; Kim, S.W.; Lee, D.S.; Hadjiargyrou, M.; Touitou, E.; Ainbinder, D.; et al. Highly cited research articles in Journal of Controlled Release: Commentaries and perspectives by authors. J. Control. Release 2014, 190, 29-74. [CrossRef]

54. Fu, Y.; Kao, W.J. Drug release kinetics and transport mechanisms of non-degradable and degradable polymeric delivery systems. Expert Opin. Drug Deliv. 2010, 7, 429-444. [CrossRef] 